\title{
Analysis of Academic Stress Levels Among Migrant Students
}

\author{
Nirwana Permatasari ${ }^{1, *}$, Dewi Retno Suminar ${ }^{2}$ \\ ${ }^{1}$ Doctoral Program at the Faculty of Psychology, Universitas Airlangga and Psychology Study Program, \\ Faculty of Medicine, Hasanuddin University \\ ${ }^{2}$ Faculty of Psychology, Airlangga University \\ *Corresponding author. Email: nirwana.permatasari-2021@psikologi.unair.ac.id and nirwana@unhas.ac.id
}

\begin{abstract}
Adaptation to new environments is critical to the successful engagement of overseas students with their studies at university. Leaving and studying in places of different societies socially and culturally can have certain social and psychological impacts. Overseas students' failure to adjust to college and their overseas environment can cause negative consequences: academic stress. This study aims to determine the level of academic stress in overseas students. This research uses a descriptive quantitative approach. The sample amounted to 167 overseas students from Eastern Indonesia at various universities in Indonesia. Data collection was done using the student-Life Stress Inventory (SSI) Scale. Based on the data analysis, it was obtained that the average overseas student has stress in the moderate category. These results indicate a variation in the stress experienced by overseas students in adjusting to their studies at the university. This research is expected to consider the university to prepare intervention programs that can be applied to overseas students in the first year of their studies.
\end{abstract}

Keywords: Academic stress, college adjustment, overseas students.

\section{INTRODUCTION}

Studying at the university provides several new challenges to students related to academic demands, autonomy to personal needs and activities, and more independence in the learning that is different from the demands of education at the previous level. This makes students need to master how to organize new social environments, develop orientations based on the institutions in which they are accepted, become productive community members, and adapt to new roles and responsibilities. In other words, to survive in university, students are required to be responsible for their actions. The transition period of the first well year also includes independent functions in the ability to negotiate with the new, more complex world, develop internal motivation to learn, manage time and finances better, attend classes, and do the task better. Studying at university provides several new challenges for students, associated with academic demands, autonomy to personal needs and activities, and more independence at learning that is different from the educational demand at the level before. This makes students need to master how to organize a new social environment, develop orientation based on the institution where they are accepted, become productive community members, and adjust themselves to new roles and responsibilities [1].
Clinciu suggests that students that have less psychological, emotional, and physical preparation, could experience stress and difficulty adjusting to various demands in college [2]. Entering university should be an exciting challenge for students. Still, some research shows that most students experience several obstacles from the second to the fourth year of bullying, such as dropping out from school or not graduating on time.

This adjustment problem will be more challenging or tricky for migrant students. The phenomenon of migrant students generally aims to achieve success through better quality education in the desired field. This phenomenon is also considered an attempt to prove the quality of self as an independent and responsible adult in making decisions [3]. In the process of maturation and achieving success, migrant students are faced with various changes and differences in multiple aspects of life that require many adjustments. The important thing needed when becoming a migrant student is to make adjustments. Wijanarko and Syafiq suggest that living or studying in a socially and culturally different place is likely to have specific social and psychological impacts[4]. One of the common social-psychological impacts on them is adapting to the new environment. The major obstacles are differences in language, values, and habits beyond the issue of geographic climate. 
Language skills are necessary to adapt to unfamiliar environments. If migrants cannot speak according to their new environment, they will feel isolated. A migrant student who has entered the emerging adulthood stage should have independence in adjusting so that they are not prone to experiencing difficulties in self-adjustment [3].

Various other problems that are also faced by migrant students (international students in this case) have been formulated by some previous researchers. There is one literature review conducted [5] in the US, UK, and Australia about an effort to provide a holistic view of the issue of international student adjustment. Based on the research, there are five categories of problems that are potentially faced by international students, including personal psychological issues, academic issues, sociocultural issues, general living issues, and English language proficiency. These issues are structured to identify the factors that influence international students to adapt, so it will be crucial to help improve their adjustment. In addition, it not only has a positive impact on how the process adapts to new environments but it is also essential to predict success and engagement with their learning at university. Students' perceptions of adjustment problems must be influenced by the specific environment in which they study, so students from different institutions may face different problems and perceive the magnitude of each problem differently. In short, these differences reflect the complexity of the adjustment problems faced by migrant students. The differences in the problems faced by several students in various countries are closely related to the cultural factors in which they study (university).

The changes experienced by migrant students are different from non-nomadic students; they are required to adjust themselves to academic transitions better and things outside the academic, such as the social environment in their overseas areas. The failure of migrant students in adjusting themselves to college and their overseas environment can cause negative impacts, such as academic stress. Lin and Yi [6] mention that the unique problems experienced by migrant students are psychosocial problems, including unfamiliar with new social styles and norms, changes in the support system, and intrapersonal and interpersonal problems caused by the process of adjustment.

Gunarsa and Gunarsa explained that common problems experienced by migrant students in addition to separating from parents are the differences in the education system in high school and college, issues around social relations, economics, and the selection of majors [7]. Other problems experienced by overseas students are difficulties in language or communication, adjusting to academic culture, culture shock experiences, feelings of isolation and loneliness, financial difficulties, and other adjustments in daily life that can lead to anxiety and stress. Gadzella suggests that academic stress is a negative emotional experience accompanied by biochemical, physiological, cognitive, and behavioral changes that are perceived as burdens or exceed the resources available to each individual [8].

Based on the description above, it can be concluded that each individual will be faced with several problems in making adjustments in various situations, including in the campus environment, so that it should face these problems when it comes. These obstacles will undoubtedly be felt heavier on those who are a migrant. Living and studying in socially and culturally different places could have social and psychological impacts. The failure of migrant students in adjusting themselves to college and their overseas environment can cause negative impacts, one of which is academic stress. This study aims to find out the picture of academic stress levels in migrant students in Makassar City.

\section{THEORETICAL OVERVIEW}

Lazarus \& Folkman define stress as a resulting state from environmental changes that produce something that challenges, threatens, or even damages one's life balance [9]. Stress is also defined by looking from the point of view of the stimulus or response that a person receives and experiences. Stress is a form of relationship between the individual and his environment, that individual has demands that exceed the resources he has to make adjustments.

Stress that arises due to pressures to show achievement and excellence in increasing academic competition is called academic stress [10]. Academic stress makes students burdened by various pressures and demands in assignments and learning achievements. Academic stress experienced by students results from subjective perception of the discrepancy between environmental demands and actual resources owned by students. Papalia, Olds \& Feldman states that academic stress in children arises when expectations for academic achievement increase, whether from parents, teachers, or peers, while the expectations are not by their abilities [11].

Thoits said the sources of stressors are categorized into three types, namely: life events, chronic strains, and daily hassles [12]. Life events focus on the role of life changes that are so much and occur in such a short time that it increases susceptibility to disease [13]. A life event can be a source of stress on a person if the event requires a short period of behavior adjustment [12]. Chronic strains are consistent or repeated difficulties in everyday life. Chronic tension can affect an individual's health, including physical and psychological [12]. Daily hassles or daily problems 
that occur in everyday life require adjustment measures in a day only [12].

Lazarus \& Folkman [9] identified the stressor category as a factor in influencing stress, namely:

a. Cataclysmic Stressor

Stressor refers to major changes or events that impact several people simultaneously and occur out of control. In stressors, individuals often get support and resources that can be used to compare the behavior of others.

\section{b. Personal Stressor}

Stressors that affect individuals can or cannot be predicted by the individual but require considerable coping efforts. These stressors are often more challenging to cope with than cataclysmic stressors due to a lack of support from other individuals who have similar things.

\section{c. Background Stressor}

Stressors are a daily problem in life. This stressor has little impact on the individual, but it will interfere and cause negative stress on the individual when it occurs continuously. For example, having significant responsibilities beyond your means, feeling lonely, arguing or conflicting with friends, poor interpersonal relationships, social environments, disputes with family, and other problems.

In this study, stressors were defined as events or situations (stimuli) that demand adjustment beyond the normal ability of daily life. Reactions to stress (responses) are seen as physiological, emotional, and behavioral. A stress reaction can also be seen as an assessment (cognitive approach) by evaluating whether the stressor is relevant or irrelevant to the individual and whether a person has knowledge of/and uses effective strategies to cope with the stressor. Focusing on the need for students to understand stress, Gadzella developed a Student-life stress inventory that has nine categories of which five are stressors (frustration, conflict, pressure, change, and selfcoercion) and four are stressors (physiological, emotional, behavioral, and cognitive assessment) [9].

\section{METHOD}

The study used descriptive analysis methods to directly explore primary data using online questionnaires. The stages of descriptive analysis are collecting data related to participants' backgrounds based on the questionnaire and exploring data based on predetermined variables. Participants in this study amounted to 167 migrant students from various regions obtained using convenience sampling techniques. Data collection is conducted using the Student-Life Stress Inventory (SLSI) scale. The instrument consists of 52 items in the category of stress sources: seven items on the frustration subscale, three items on the conflict subscale, four items on the pressure subscale, three items on the change scale, and six items on the subscale of self-imposition. In the category of reactions to stress in the subscale of physiological reactions, there are 14 items, four items on the emotional reaction subscale, eight items on the behavioral subscale, and two items on the cognitive reaction subscale. In addition, researchers provide open questions to get an overview of migrant students in making college adjustments. Reliability is 0.788 . This means that the scale of SLSI is reliable.

\section{RESULT AND DISCUSSION}

The data showed the number of participants involved in this study as many as 167 people, where there $88.1 \%$ female and $11.9 \%$ male. Participants involved in the study had ages ranging from 17 years to 23 years. The participants' semester levels include semester one $20.2 \%$, semester two $4.2 \%$, semester three $26.2 \%$, semester five $20.8 \%$, semester six $1.2 \%$, semester seven $24.4 \%$, and the rest is semester above semester 8 . Regarding travel experience, $59.5 \%$ had no previous travel experience, $38.7 \%$ had previous travel experience, and the rest felt less sure. Related information on the entrance of the university can be seen as follows:

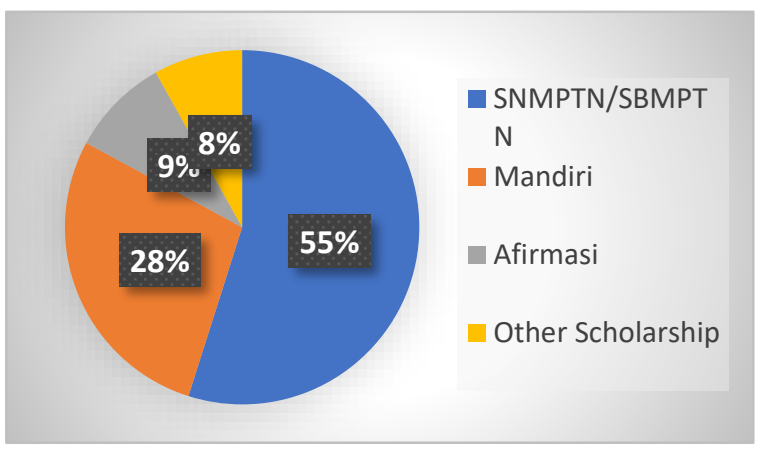

Figure 1. University Entrance 
As for the exposure of the participant's area of origin as in figure 2 below:

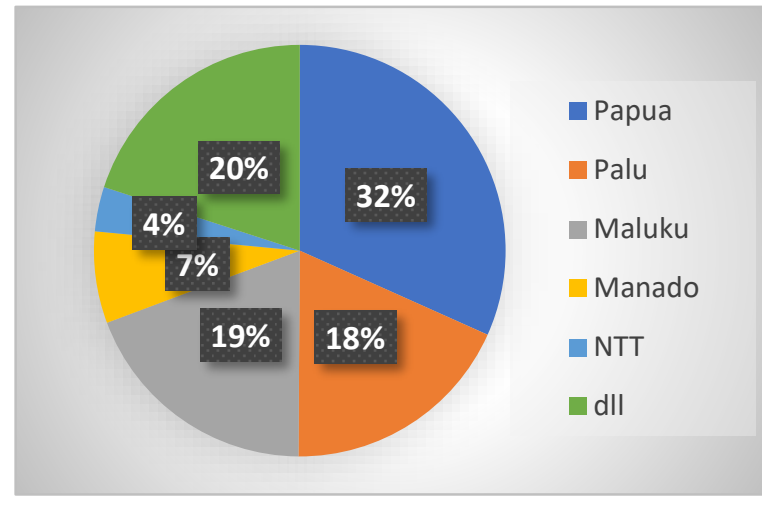

Figure 2. Regional origin

\subsection{Overview of Academic Stress of Nomads}

Based on the findings of 167 migrant students who were study respondents, obtained an overview of academic stress based on student life stress inventory in migrant students in Makassar City is in the medium category. This can be seen in figure 3 :

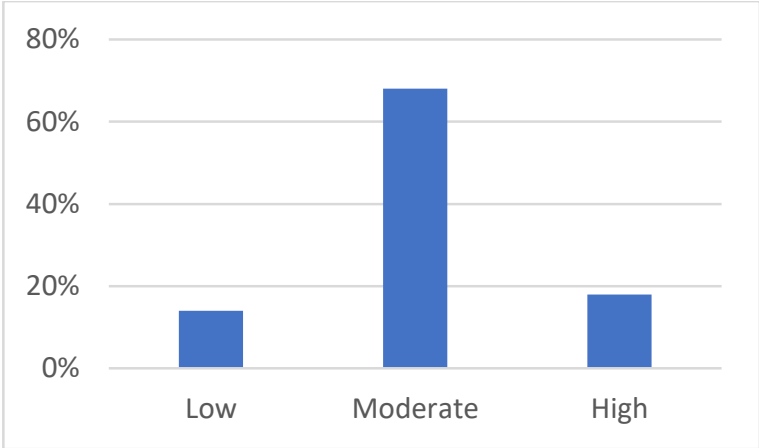

Figure 3. Level of academic stress of migrant students

Based on figure 3, it is seen that migrant students who have academic stress levels in the low category as much as $14 \%$ (24 people), moderate categories as much as $68 \%$ (113 people), and high categories as much as $18 \%$ (30 people).

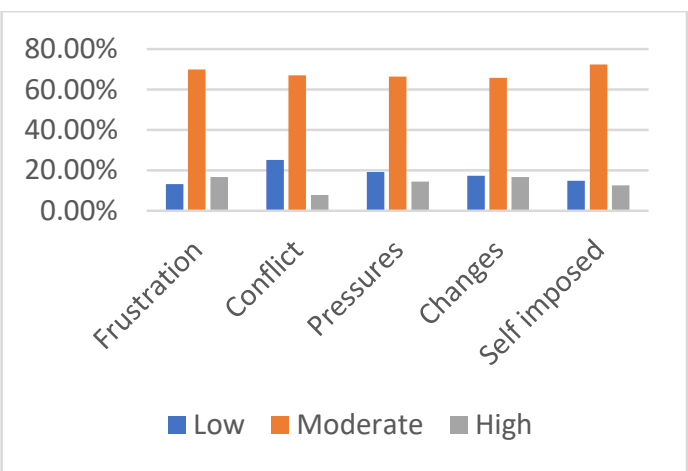

Figure 4. Category of sources of stress

Figure 4 shows the percentage of the number of study respondents based on the level category in each component of the stress source. The source of stressors consists of 5 components: frustration, conflict, pressures, changes, and self-imposed. In the frustration component, 22 people $(13.17 \%)$ were in the low category, 11 people $(70.06 \%)$ were in the moderate category, and 28 people $(16.77 \%)$ were in the high category. In the conflict component, 42 people $(25.15 \%)$ were in a low category, 112 people $(67.07 \%)$ were in the moderate category, and 13 people $(7.78 \%)$ were in the high category. In the pressures component, 32 people (19.16\%) were in the low category, 111 people $(66.47 \%)$ were in the moderate category, and 24 people $(14.37 \%)$ were in the high category. In the changes component, 29 people $(17.37 \%)$ were in the low category, 110 people $(65.87 \%)$ were in the moderate category, and 28 people $(16.77 \%)$ were in the high category. In the selfimpose component, 25 people (14.97\%) were in the low category, 121 people $(72.46 \%)$ were in the moderate category, and 21 were in the high category. Based on the description, it can be concluded that the level of frustration and changes components of respondents has a high tendency, whereas conflict and pressures components have a low tendency.

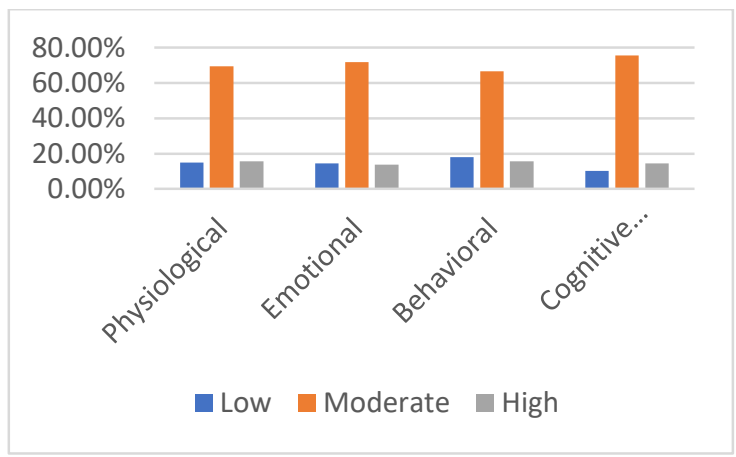

Figure 5. Category of reactions to stressors

Figure 5 shows the percentage of the number of study respondents based on the level categories on 
each component of the stress reaction. The category of reactions to stressors has 4 components: physiological, emotional, behavioral, and cognitive appraisal. In the physiological component, there are 25 people $(14.97 \%)$ in the low category, 116 people $(69.46 \%)$ are in the moderate category, and 26 people $(15.57 \%)$ are in the high category. In the emotional component, there were 24 people $(14.37 \%)$ in the low category, 120 people $(71.86 \%)$ were in the moderate category, and 23 people $(13.77 \%)$ were in the high category. In the behavioral component, there are 30 people $(17.96 \%)$ in the low category, 111 people $(66.47 \%)$ are in the moderate category, and 26 people $(15.57 \%)$ it's in the high category. In the appraisal cognitive component, there were 17 people $(10.18 \%)$ in the low category, 126 people $(75.45 \%)$ were in the moderate category, and 24 people $(14.37 \%)$ are in the high category. Based on the description, it can be concluded that the level of physiological and behavioral components of respondents has a high tendency, whereas emotional and cognitive appraisal components of respondents have a low tendency.

\subsection{Open-Ended Questions}

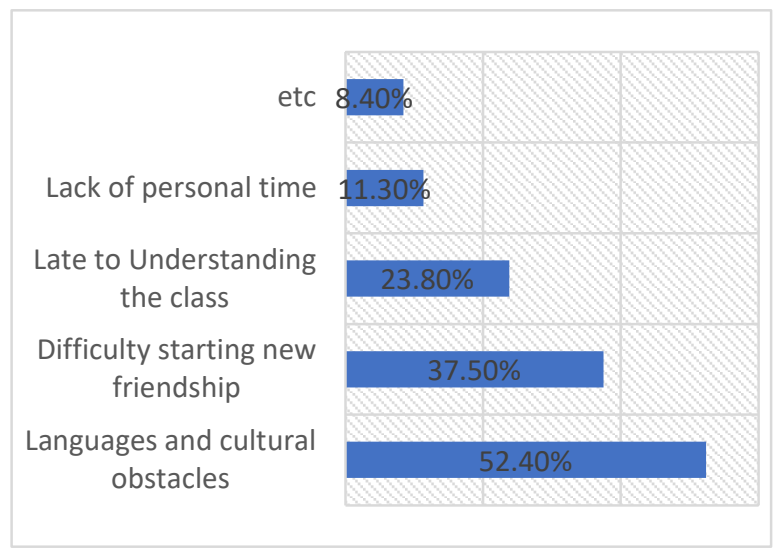

Figure 6. Internal problems faced by first traveled in adjusting at the university.

The internal problems faced in adjusting to university life when the migrant students first travel, consist of language and cultural obstacles (52.4\%), difficulty starting new friendships $(37.5 \%)$, late to understanding the class $(23.8 \%)$, lack time personal time $(11.3 \%)$, and others such as transportation problems, feeling confused and afraid of the college environment, less able to manage time.

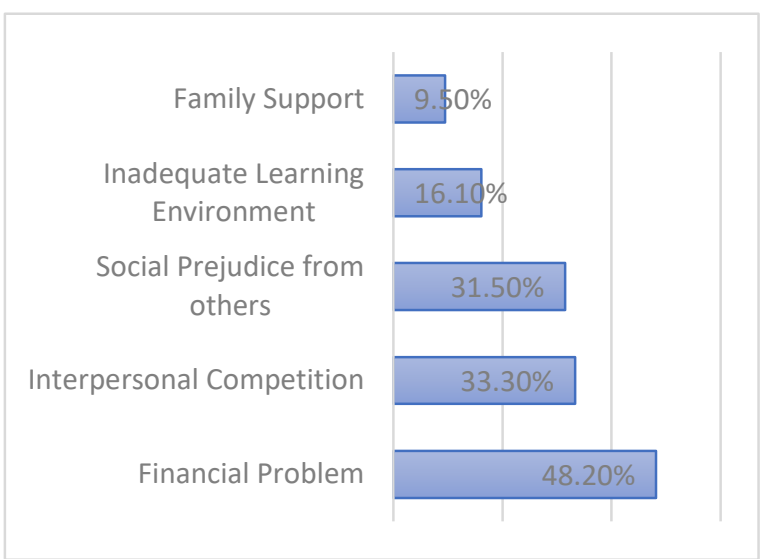

Figure 7. External problems faced first in adjusting at the university

Figure 7 describes the external problems encountered in adjusting to university life when the migrant students first travel. The most widely revealed were related to financial problems $48.2 \%$, interpersonal competition $33.3 \%$, social prejudice from others $31.5 \%$, inadequate learning environment $16.1 \%$, family support $9.5 \%$, and others such as religious differences, difficulty adjusting to new friends, and lacking support.

\section{CONCLUSION}

Adjustments to the university environment face many processes that should be done during the first year that demands the ability to maximize personal resources. Adjustments must take into account the final results, adaptation functions, and the process itself. When students can through from the first stage, which tends to produce emotional tension and stress, they can reach the process of the final stage of the college with more well-being conditions and adequate adaptation functions. Based on the findings, it was concluded that the picture of academic stress levels in migrant students in Makassar City is in the moderate category, where the adaptation of university life requires skills to cope with the various source of stress so that students could fulfill the demands of his development as a student.

\section{AUTHORS' CONTRIBUTIONS}

Nirwana Permatasari contributed to conceptualization, methodology, investigation, validation, analysis, and writing. Dewi Retno Suminar contributed to conceptualization, methodology, investigation. All authors reviewed the results and approved the final version of the manuscript. 


\section{ACKNOWLEDGMENTS}

For participants and all parties involved in this study.

\section{REFERENCES}

[1] Arjanggi, R. \& Kusumaningsih, L.P.S. College Adjustment of First-Year Students: The Role of Social Anxiety. Journal of Educational, Health, and Community Psychology, 5(1), 2016, pp. 30-39.

[2] Clinciu, A. I. Adaptation and stress for the firstyear university students. Procedia-Social and Behavioral Sciences, 78(1), 2013, pp. 718-722.

[3] Santrock, J. W. Life-Span Development. New York: McGraw-Hill. 2010.

[4] Wijanarko, E. \& Syafiq, M. Studi fenomenologi pengalaman penyesuaian diri mahasiswa Papua di Surabaya. Jurnal Psikologi Teori \&Terapan, 3(2). 2013.

[5] Wenhua, H., \& Zhe, Z. International students' adjustment problems at university: A critical literature review. Academic Research International, 4(2), 2013, 400-406.

[6] Saniskoro, B.S.R., \& Akmal, S.Z. Peranan penyesuaian diri di perguruan tinggi terhadap stres akademik pada mahasiswa perantau di Jakarta. Jurnal Psikologi Ulayat, 4(1), 2017, 95-106.

[7] Gunarsa, S.D. \& Gunarsa, Y.S.D. Psikologi Perkembangan Anak dan Remaja, Jakarta: Gunung Mulia, 2004.

[8] Gadzella, B. M. Student-life stress inventory: Identification of and reactions to stressors. Psychological Reports, 74(2), 1994, 395-402.

[9] Lazarus, R. S. \& Folkman, S. Stress Appraisal and Coping. Network: Springer Publishing Company, Inc, 1984.

[10] Alvin. O, Handling study stress, Jakarta: Elex Media Komputindo, 2007.

[11] Papalia, D. E., Old, S. W., \& Feldman, R. D, Human Development (Psikologi Perkembangan) (9th ed.), Jakarta: Kencana, 2008.

[12] Thoits, P. A. Stress, coping, and social support processes: where are we? What next? Journal of Health and Social Behavior, vol. 35, 1994, 53-79. http://www.jstor. org/stable/2626957.

[13] Lyon, B. L. Stress, coping, and health. In Rice, H. V. (Eds.) Handbook of stress, coping and health: Implications for nursing research, theory, and practice, USA: Sage Publication, Inc, 2012, pp. 3-23. 